\title{
Remarks on the Conceptualization of the Educational Problem in the Muslim World: The Case of Algeria
}

\author{
Omar Nakib \\ National High School for Teacher's Education (E.N.S), \\ 93 Ali Remli Street, Bouzareah, Algiers, Algeria. onakib@yahoo.com
}

DOI: https://doi.org/10.22452/usuluddin.vol48no2.6

\begin{abstract}
This study is a reflection into the methodological considerations that must be adopted to tackle the educational problem in the Arab and Muslim countries: the case of Algeria. The purpose is to discuss those methodological considerations that may pave the way to an objective approach of the educational problem in Algeria. This is to provide the researchers with some methodological tools to formulating the educational problem. An attempt has been made to address research questions, i.e. How should we conceptualize the educational problem in the Arab and Muslim countries: The case of Algeria? To conclude, this reflection requires us to give more importance to these methodological considerations to be able to state the educational problem in the ArabMuslim lands in the appropriate manner. And, the elucidation of the concept of the 'problem' in educational research is an inevitable necessity. This is to pave the way for Muslim educational theorizers to grasp the essential components of the educational problem as a basic step to resolve it. The reason is that the educational problem is one of the important challenges facing the modern state and the epicentre of the current global civilizational conflict. The desired model of man, is the pivotal concern of philosophy of education. That is why, the educational problem in the ArabMuslim lands is how to re-qualify the contemporary Muslim man to move from the state of being a backward man to the state of a civilized human being.
\end{abstract}

Keywords: educational problem, philosophical approach, desired model of man, Arab-Muslim lands, cultural peculiarities, global citizen

\section{Introduction}

Education in the Arab-Muslim countries has become one of the dilemmas that successive political systems have not been able to grasp its essential elements, let alone dealt with properly, in such a manner that may lead us to the development of an educational policy that enables the people of these countries to eradicate themselves from the situation of centuries-long civilizational backwardness. Perhaps one of the most important things behind this 
crisis is the inability of those in charge of the national educational project, in particular educational theorists, to adopt sound and appropriate methodological approaches to the nature of the educational problem as it is in the actual reality of the Arab countries and Muslims and not as we intend it to be, based on prior intentions to achieve some very limited interests, that do not serve the interests of the entire nation, but rather it serves the interests of the status quo. Through addressing a set of research questions, an attempt is made to review the determinants or methodological considerations that any researcher should pay attention to in the educational problem in the Arab countries and Muslims in order to be able to formulate it in a way that ensures proper understanding that may leading us to suggest appropriate solutions to the existing problems of education.

\section{What Do We Mean by "Education as a Problem"?}

The educational problem is one of the most important challenges facing the modern state. It has also been considered since time immemorial not only for educators, but also for intellectuals and social reformers; and even politicians and economists as an essential element of the entire civilizational problem that any society may face at any stage of its long history ${ }^{1}$.

So, it would be axiomatic to consider the educational problem as the epicentre of the global civilizational conflict taking place in the globe at the current stage of human history. This is evidenced by the insistence of the major economic and military powers, in the world of today, led by the U.S.A, to continue to put its pressure on the countries that are labelled to be the source of the so-called "global terrorism" in order to make them adjust their schools" curricula in accordance with the requirements of the Western model of education. However, the real intention of such a campaign is to prevent the emergence of any kind of successful educational models over the world that may represent in the future the alternative that may threaten or, at least, able to compete with the Western model of education and, as a result, to harm its reputation and credibility over the world. The latter is intended to be the only cultural and

1 M. Abbassi, Mushkilāt Tarbawiyah fì al-'Ālam al-Islāmī, (Problems of Education in the Muslim World) ( $2^{\text {nd }}$ edition, Mecca al-Mukarramah, Saudi Arabia: al-Manara Publishing House, 1989), p.13. 
educational model that must prevail and reign in the world. This is based on the idea of 'The End of History and the Last Man', that is, the 'White Man' as the one and only model capable to lead human race until the end of its existence in history.

Many Muslim thinkers consider human being as the central factor of the problems of civilization. This is the case, for instance, of Malik Bennabi in Algeria and Syed Naquib al-Attas in Malaysia ${ }^{2}$. Such a vision summarizes the educational problem as we are facing in modern and contemporary Muslim world. Hence, the Muslim backward man as a decomposed human being is at the origin of the various problems, we are facing in our contemporary Muslim world ${ }^{3}$. Meanwhile, other thinkers do not see the necessity to emphasize the human factor in the formulation of the problems of civilization. However, they stress the centrality of political and economic institutions ${ }^{4}$ in the emergence of what is labelled in Malik Bennabi's legacy as the 'Islamic problem's.

Actually, as we see it, such an approach does not deal with the essence of the problem, but, instead, with its symptoms and manifestations. As a matter of fact, it seems to us that the approach that emphasises the human factor is conceivable since the different society's institutions are in fact, the product of the human factor. It is he who produced such failed institutions, unable to perform their function $^{6}$ to develop and promote human life.

As for philosophers of education interested in theorizing of education, the problem of the desired educational model is one of the most important issues whenever there is an attempt to formulate a theory in education. It is considered as a basic and fundamental requirement for the theory of education to be considered as a theory.

We mean by the expression 'the desired model of man', the nature of the desired citizen we intend to produce on the ground through the application of the process of education we are

2 For more details, see for example: Syed Muhammad Naquib Al-Attas's "The Concept of Education in Islam", and Malik Bennabi's "Wijhah al- 'Ālam alIslämī" (Islam in History and Society).

3 Malik Bennabi, Wijhah al-'Ālam al-Islāmī (Islam in History and Society) (Damascus, Syria: Dār al-Fikr, 1986), p.37.

4 There are many trends that emphasize the centrality of the political dimension of the "Islamic Problem" such as al-Afghānī al-Nabhānī and others.

5 Malik Bennabi, Wijhah al- 'Ālam al-Islāmī, p.37.

6 Malik Bennabi, Wijhah al- 'Ālam al-Islāmī, p.51. 
undertaking through socio-educational institutions. However, it must be emphasized that the notion of the 'the desired model of man' is fundamentally cultural in its nature since it is related to the cultural ideals of society and its aspirations in history, and education is the mean through which those ideals and aspirations are being achieved

As it is obvious in the literature, the issue of the desired model of man is an unanimous matter among researchers ${ }^{7}$, who are interested in curriculum development and design. However, the nature of the model to be adopted and its details are a controversial issue. Cultural peculiarities are the main source of such a controversy. So, it is an unavoidable intellectual confrontation. This is, we may argue, why education has become more than ever the epicentre of the current global political conflict in the contemporary world?

The desired model of man, as we have already pointed out, is one of the most important issues that concern philosophers of education and those interested in educational theorizing. Therefore, it is, in fact, a prerequisite for any educational project that seeks to build individual's personality and qualifies him to perform his mission in history according to a specific cultural vision adopted by society. Furthermore, educational reform stems from an educational philosophy inspired by the actual needs of both, the present and the foreseeable future. The purpose of such a philosophy is to develop a clear vision about the desired model of man, as the starting point of the process of education in order to achieve the project of civilization. It also constitutes, in another sense, the cultural component that distinguishes a given society from another.

\section{Stating the Problem in Educational Research}

Due to the importance of the problem statement in educational research, the elucidation of the concept of the 'problem' in the field of educational research is an inevitable necessity. Therefore, we emphasize that "reality as a whole, is based on the law of order of

7 T. W. Moore, Philosophy of Education: An introduction ( $2^{\text {nd }}$ edition, London and New York: International Library of Philosophy of Education, Routledge and Kegan Paul, 1986), p. 35. 
things ${ }^{8}$. So, it is inconceivable that historical facts are the embodiment an anarchic world. The correct scientific knowledge is the 'fruit' of correct knowledge of the existence of the law of order in any phenomenon in the world ${ }^{9}$, be it, biological, social, psychological, historical, etc. For instance, the cellular composition of the biological phenomenon is naturally in an interactive relationship conducted according to a universal law that guarantees the normal functioning of its system and ensure continuity and safety of biological life of the organism.

By the same token, education as a social phenomenon must be approached, that is, in terms of its being a phenomenon subject to the law of order. So, any kind of stumbling, stopping, or disruption of the normal functioning in the life of such a phenomenon is an indication of a certain defect that has afflicted the law of order on which the functioning of this phenomenon is based ${ }^{10}$. Then, this is an evidence of a crisis in it, that is, a problematic situation that needs to be taken into consideration in order to enable the phenomenon to recover its position in the law of order, I mean, to resume its normal functioning. Such a problematic situation is, often, at the essence of any research endeavour since scientific research, in general, is either an attempt to resolve an existing problem, or an attempt to produce new knowledge that will help us in the future to tackle the same problem in order to resolve it $^{11}$.

Based on the above analysis, we can conclude that in natural cases where human mind is used in a systematic manner, it would be able to grasp the actual reality of the phenomenon as it is in the real world. And, as a result, our understanding of this reality is strongly expected to be accurate, if not totally true. Hence, there is no contradiction between the actual reality of the phenomenon as it is and our understanding of such a reality. However, in some cases,

8 Syed Naquib al-Attas, "The Concept of Islamic Education" (the keynote address delivered at the "First World Conference on Muslim Education", Mecca alMukarramah, 1977), p. 7.

9 M. Abbassi, Al-Nawiyah al-Tarbawiyyah fì al-Bilād al-Islāmiyyah (Quality Education in the Muslim World: Epistemological Analysis of the Educational knowledge) ( 1 $^{\text {st }}$ edition, Saudi Arabia: Maktab at-Tarbiyyah al-'Arabī li Duwālī Khalij, 1989), p.13.

10 M. Abbassi, Al-Nawiyah al-Tarbawiyyah fĩ al-Bilād al-Islāmiyyah, p.13.

11 This idea is the expression of the difference between fundamental and applied research. 
where human mind does not adopt such an approach to deal with the reality of any phenomenon and do not observe the rules of methodology, the mistake that some novice researchers may make is that we tend to understand the phenomenon as they want to see it and not as it is the actual reality. Whereas, the problem is a systematic formulation of the reality as it is in the actual world and not as we want it to be.

Furthermore, reality, as the subject of any study, is either in a state of order and regularity, or in a state of chaos and disorder. The first situation, which is the state of order and regularity, is the natural state of any phenomenon and it is fulfil its function in its normal way. The second situation, the state of chaos and disorder, is the indicator that shows the existence of a problematic situation that manifests itself through contradiction between the elements, disorder in the functioning. It is indeed an abnormal situation that needs to be approached in order to determine the factors of such a failure and to look for the possibility to contribute in its recovery and resume its original function in its normal way

Science is based on two main parts: the subject matter and the methodology. If one or both were absent, there was no science at all. As for the subject, it is the truth as it is in reality. As for the method, it is the tool we use to understand this reality as it actually is and not as we want to understand it. By this way, science becomes the appropriate way by which we come to grasp the reality of any phenomenon on one part, and understand the contradictions that may arise from the interference of parasitic factors in the normal and harmonious functional interaction between the elements of this phenomenon on the other part. The latter is the problematic situation that novice researchers, in particular, should pay attention to, understand, and grasp its dimension in order to be able to explore the possibilities of treating it in such a way that can enable it again to resume its function in its proper way.

In order to clarify the previous idea, we point out that life is based on a set of consistent laws that guarantee the normal and regular course of life. However, it may arise in some societies during a determined period of its history some kinds of abnormal situations, which may impede its system from performing its function so as the social life is shaken and disturbed; then the society itself fails in performing its historical function naturally. 
This situation may reach the point where the whole community system may stops working in a normal way. The same applies to any phenomenon in the societal life. However, in the context of this article, we are concerned with the educational phenomenon.

The degree of rift and disturbance, referred to, varies between communities and nations and, depends on the type and impact of factors that influence the social system. If the factors affecting it were minor, the fracture was too. Therefore, what we envisage as a solution to remedy that situation should be accordingly. Whatever the situation is, such a problematic fact requires us to look at the nature of the problem, its causes and effects, in order to be able to formulate, analyze and interpret it, and then working out for the possible solutions. In such situations, the "disturbed" reality will not return back to its original state of order unless we manifest a certain ability to control the factors causing such a situation and try to reach its state of harmony that enable its elements to interact positively, and perform its function in a normal way as it is expected from it.

The way we use in formulating the problem represents the methodological approach that helps us to understand, explain the research problem and suggest the appropriate procedures to treat it. Therefore, it represents on the other hand, the methodological starting point for dealing with the research problem and drawing up a plan to treat it properly. As for the incorrect formulation of the problem, all the results that follow will be incorrect as well. And then, it becomes inevitable to return back to the starting point, that is, to reconsider our way of formulating the problem as it represents the state of contradiction between what is being and what ought to be. Based on this consideration, there is a need to point out to what we can be observed in many studies that do not pay enough attention to formulating the research problem in the required correct way.

As we often notice the absence of a clear link between research titles and research problems that are formulated in that research and the goals that we wish to achieve through achieving them, which makes this research unable to reach scientific results that can be invested in supporting the development project.

Thus, it seems clear to us that the correct formulation of the problem is the basic prerequisite, and the window through which we can achieve the proper handling of the various problems of man, 
society and civilization if we want our research and studies to answer our questions and achieve results that can contribute to reducing the severity of chronic problems that We suffer from it in Arab countries and Muslims in general.

It has become well-known to the Arabs and Muslim in general, that our educational systems were and still suffering from a defect in their essence, as despite several decades of national independence in the Arab countries, these systems are still unable to achieve our historical aspirations by the mean of undertaking a qualitative educational shift that may transfer the Muslim man from the position of the underdeveloped person to the position of the civilized person. Among the most important factors of this deficit, in our opinion, is the absence of an integrative, philosophical and authentic vision. In other words, the absence of a philosophical approach that grasps the essential of the historical reality as it is, and meets its demands and needs.

\section{What Do We Mean by the Philosophical Approach in This Context?}

The approach is the holistic perspective the researcher adopts to address a research problem in order to understand, analyze and treat it. As it should be, every researcher has his own vision from which he deals with any research problem, based on some theoretical considerations, known in the literature as the "theory of research". However, it is useful here to point out that the approaches vary in terms of type and nature. As for its type, we are concerned with the field of specialization in which the approach is classified, such as being a political approach, economic, historical, or philosophical, and so on. As for its nature, such as being a holistic approach, or a partial, a qualitative, a quantitative or a mixed approach, which combines the two approaches, qualitative and quantitative, and so on.

Therefore, we see that the most appropriate approach to the correct handling of research problems is the approach that formulates the research problem as it is in its actual reality and not as we tend to understand it, so as we try to impart to it our understanding and interpretation due to some pre-determined considerations, be it, political, ideological and so on. Indeed, sometimes we are droved by our feelings and our whims are also 
for purposes that we predetermine, or another purpose that does not serve the scientific truth as it is in reality per se. By this remark, we mean the truth as it is evident in its historical context in which it arose, and as a true expression of the contradiction between ' what ought to be' and 'what is being' as an expression of the crisis experienced by human activity, such as educational, political, or economic activity.

As we see it, such an approach to deal with research problems is not the product of modern history; as it is rooted in the dawn of history of science and scientists and particularly during the Islamic civilization era. Amongst the most famous field of scientific specialization that adopted such an approach in our Islamic heritage, is Islamic jurisprudence by virtue of its being a kind of approach that can be seen as a process of systematization of the mind that obliges it to respect the methodological rules of work while dealing with any research problem. In other words, it is the science that provides us with the methodological rules that regulate the work of the mind in such a way as to ensure the logical connection between the elements of the problem, that is, to match between its factors, manifestations and effects. This is the right way to prospecting the resolving of the problem.

\section{How to Match Between the Philosophical Approach and the Formulation of the Educational Problem?}

As a starting point, we need to answer such a question: How do we link the philosophical approach we adopt, to the formulation of the educational problem? I mean, how to enable the adopted philosophical approach to guide our understanding of the problem in order to ensure an accurate statement since it is an objective reality but peculiar to the cultural frame of reference and civilizational stage the concerned society is witnessing.

Based on what has been shown previously, it becomes obvious that the nature of the approach adopted by the researcher has a clear impact on the elaboration of his vision of the research problem, and its understanding, analysis, interpretation and methods of treatment. That is, if the adopted approach is holistic in nature, then our view of the problem is holistic as well. If it is a partial one, then our view of the problem is partial too. 
Accordingly, another question arises and becomes more important than formulation of the research problem itself: What is the nature of the approach that one should adopt as we are facing the problems of post-independence era in the Arab and Muslim countries? What exactly is needed? Is it a holistic approach that looks at our problems as a problem of civilization or a partial approach to aims to formulate some responses to the partial and daily-life problems? Be it, economical, ethical, religious, political, and so on.

On the basis of the above, we allow ourself to define the question in the field of educational research as follows: What is the nature of the philosophical approach that we should adopt to address the educational problem in the Arab and Muslim countries?

\section{Educational Problem as the Basic Source for the Formulation of Aims of Education}

It should be noted here that the educational aims are one of the most important issues that took the attention of philosophers of education and those interested in theorizing for education in general ${ }^{12}$. In fact, it is a prerequisite for any educational project that seeks to build the desired model of citizen and prepare him to fulfil the requirements of his mission in life as it is prescribed in the society's cultural worldview. As a matter of fact, it becomes axiomatic for the educational theorizers that any project of educational reform is based on a certain educational philosophy that reflects the cultural ideals of society and its historical 'aspirations'.

Based on the above consideration, the starting point in any educational reform project is the elaboration of the desired model of man, education should strive to achieve through a purposeful and systematic process.

Hence, it is Culture that inspires such an educational philosophy by virtue of its being the principal source of inspiration of the society. However, educational theorizers are usually inspired by both, cultural frame of reference of the society as well as the actual needs and requirements of the historical stage that society is witnessing.

Grasping in an accurate manner the changing historical conditions of the society has a direct impact on the quality of the

12 T.W. Moore, Philosophy of Education: An introduction, p. 35. 
performance of the educational institutions. So, developed nations have continuously striving to review the philosophical education and in particular, the educational aims and objectives, rather, the desired model of man. This is to adapt the education theory and practice in function of the new challenges society is facing at a determined stage of its history in order to elaborate new educational policies that enable them to meet the requirements of the new era. This process is an ordinary matter in the developed nations that have controlled the meaning and objectives of education. However, it becomes an unavoidable requirement for the Arab and Muslim countries if they are to get out of the persisting multi-dimensional state of backwardness.

However, it is important to mention a matter of a particular importance in this context. It is the issue of the relationship between the educational problem and the aims and objectives of education. One of the tenets upon which educational theorizing is based is that the formulation of the educational problem is the starting point to formulate the aims and objectives that should be adopted by the educational project in any society.

By virtue of its being the central factor of the problems of civilization and at the origin of the different problems, society is facing at any stage of its history, educational theorists usually, emphasize on the human factors. For the Algerian context, as an example, the educational problem can be stated by the following question:

How can we reformulate the personality of the contemporary Algerian man so that he can move from the position of the underdeveloped person, to the status of a civilized person who is qualified to successfully perform his mission in history?

As a matter of fact, any attempt to set the aims and objectives of education to develop a new educational curriculum for various educational stages out of the consideration of this 'historical reality' is no less than a waste of time, efforts, and money.

The desired model of man that we seek to achieve through the educational reform project is, in fact, the resolving of the educational problem faced by society. The latter is that we have previously formulated as an actual problem based on real facts and not as we tend to imagine in our minds, usually, based on prejudices 
serving for specific agenda that may not have any scientific significance.

Many Muslim and non-Muslim thinkers adopted this approach in formulating the educational problem. Among these thinkers, we find the Algerian thinker Malik bin Nabi. A reflection into his intellectual works related to the problem of civilization, and particularly in the Muslim world, we find that he pointed out to some parameters that he sees the necessity to be observed and took into consideration if we are to successfully deal with the educational problem and succeed in the achievement of the educational reform project $^{13}$. His central concern was the human factor by virtue of his being the subject, the aim and the mean at the same time, as he stated it: From the man, the entire Islamic problem originates, especially in Algeria. ${ }^{14}$

This note indicates the centrality of the human factor in the emergence and spreading of various manifestations of the civilization crisis in Arab and Muslim lands; and that if we want to put the finger on the disease, then we only have to turn to the human being and look in the situation that has fallen into it and how it can be helped to get out of it.

\section{The Desired Model of Man and Society as a Problem Facing the Educational Theorists}

The aims of education are formulated in the form of an ambition, which society desires to embody in its future generations. Its expresses this ambition by formulating the model of man that society must seeks to achieve, and sees it as an embodiment of his aspirations in history. This becomes obvious especially when we look into the ideas and views of philosophers and thinkers who summarized them in what is known as: General Theories of Education. This type of theory, which is matched with another type called the Specific Theories of Education ${ }^{15}$, is usually built on the basis of adopting a specific model for the individual as perceived by the fathers of the people and their educators but inspired by

13 For more details of these parameters see: Omar Nakib, "Malik Bennabi's Ideas and Views on Civilization and the Development of Society. Perspectives on Education" (Ph.D Thesis, Universiti Putra Malaysia, 2004, (non-published).

${ }^{14}$ Malik Bennabi, Wijhah al- 'Álam al-Islāmī (Islam in History and Society), p.38.

15 T.W. Moore, Educational Theory: An Introduction, p. 7-10. 
culture as the principal frame of reference adopted by society. However, the question that imposes itself is: What is the nature of the educational model that society should adopt in order to achieve its aspirations in history? In fact, there are two ways to answer this question.

The first way is at the origin of the whole issue, and it encompasses the necessity to define the concept of education we adopt. I mean: how education should be understood as a project to build a civilized society by preparing human being for life and his mission in life, a kind of preparation that should help enable society to be actively present in history. This is because when we refer to the related literature, we can identify various conception of education among philosophers, thinkers and scientists; and in some cases, such diversity may reach a degree of controversy and antagonism. In fact, this diversity has occurred because of a number of factors that undoubtedly influence those who deal with this concept in terms of analysis and formulation. Perhaps the most important of these factors are cultural peculiarities that distinguish a given society from another.

To be clearer, is education, for example, teaching people to say or write beautiful things? Or is it the preparation of the individual for a particular professional occupation that helps him to earn a living build a family and have a child? Or is it preparing him for a specific social role that supports the existence of the society in history and the continuation of this existence? Is this role at the level of society in which he lives or beyond it, that is, the nation to which it belongs, or should it reach a broader perspective of the "global citizen" who believes that his mission is not limited into the boundaries of society to reach the whole world? Or is it the formulation of the good person who carries out a divine message to all humanity? So, what is our vision of this issue?

The reason of posing this question is because the nature of our vision about this issue has a profound impact on the whole project of educational reform. That is why many scholars considered the issue of defining the concept of education as a standard issue, (A Commitment to Value ${ }^{16}$ ) which cannot be bypassed without specifying a clear and decisive position before undertaking any attempt to develop the sought educational curricula and identifying

16 T.W. Moore, Philosophy of Education: An introduction, p. 28. 
approaches to the development, implementation and evaluation of the curricula.

The second way is to show obviously what we are seeking to achieve through the educational project of reform we are carrying out in our schools and other societal institutions. Therefore, the question that arises here at this level is: What is the nature of the desired model of man we seek to achieve through the educational process?

When we refer to the historical experience of education throughout history to the richness of this experience through what can be seen from the suggested educational models of 'human being' to be prepared through education. historically spoken, educational thought sought through the different views about the desired model of man to suggest visions oscillating between the transcendental idealism and physical status to find a model to be used to confirm the legitimacy of his assumptions so as it imparts to it a certain value, give it a kind of holiness that requires some kind of binding leading to commitment. Thus, it is clear to us that for every historical age, rather, for every human and social project, there is a determined model to be adopted and sought to be achieved on the 'ground'. That is why every nation is continuously seeking to present its educational model as the closest model to succeed in the achievement of the society's historical aspirations and the resolving of its problems.

As a matter of fact, philosophies of different walks and orientations have sought to 'preach' for their models and strive to achieve them in real life. It may not only strive to achieving it, but rather to call for it as the most appropriate model to be followed. And, sometimes they become motivated by unethical way, logic of force rather than logic of reason as an attempt to force them to adopt such a model. Such an attitude is no less a kind of global arrogance. This is manifested in the Western and American foreign policy particularly in the countries that have been 'charged' with terrorism. That is why we see globalization as a mere attempt to impose a single view based cultural model on all nations and peoples that deals with any opposition with all possible ways of coercion, violence, distortion and abuse while pretending to be civilized and defending human rights. 


\section{How Should We Understand the Educational Problem in Arab and Muslim Countries? The Case of Algeria}

Due to the historical circumstances experienced by the Arab and Muslim countries after their independence from the colonial powers, most of their political systems adopted the socialist model of education. They saw in it the appropriate model for the situation in which most of these countries were experiencing. It was in line with the aspirations of poor and deprived peoples who had just extracted themselves from the colonial stage. Also, this model, as they saw it, is the right way to find rapid and effective solutions to many urgent problems such as poverty, ignorance and illiteracy, and getting out of the cultural and economic chaos inherited from the colonial era.

However, in Algeria, for instance, this experience proved its inability to achieve both, individual and societal aspirations to progress and prosperity. Therefore, it was necessary to think about an alternative way that might help to avoid further backwardness and dependency that may deepen the state of decline. Thus, new initiatives have emerged to implement a comprehensive development project, particularly in the field of education, as a central part of this project. So, the objectives-based approach has been adopted as a reform alternative to address the educational problem. However, those reforms were in vain because the nature of the educational problem that was and still facing us is how to requalify Algerian people to resume their historical role in building the "new Algeria" in the post-independence era.

Unfortunately, despite all the efforts undertaken and the positive 'partial' achievements that have been made in many fields of education, such as increasing the number of students and reducing illiteracy and the clear development in organizing and structuring the educational system, the failure, however, remained the inherent characteristic and the outstanding feature of the Algerian national educational project, either in Algeria, not to say: the remaining parts of the Arab and Muslim world in general as well. This is because, as long as it is unable to produce the desired educational transformation in the Muslim man personality as the starting point to eradicate man and society from the state of being unable to perform our historical mission as prescribed our principal 
frame of reference, the Islamic Weltanschauung, it will remain in such persisting of decline.

It is also important to note that another educational reform project had been initiated in the beginning of the new millennium, specifically in 2003 in our country. They adopted the principle of adapting education according to the idea of global culture, so that they made the term 'Global Citizen' as the principal unit of thinking and one of the utmost aims to be achieved. However, we did expect it to falter in achieving such kind of 'aspirations' because it did not focus from the beginning on changing 'mindsets' as the point of departure in the achievement of such a project by the way of accommodating them to the dimensions of global culture with its dual aspect ${ }^{17}$ so that it can be used to serve the goals of the comprehensive national development project and not the goals of the educational globalization project as a way to globalize society and dissolve its historical, cultural, religious and linguistic identity.

As we see it, the above analysis may pave the way for us to elaborate the nature of the approach that we are supposed to adopt to address the educational problem we are facing in the Arab and Islamic world in general and Algeria in particular. Therefore, we affirm that in this reflection we adopt a civilizational approach that sees education as a cultural project which aims at building the advanced society through the preparation of the civilized man, by virtue of his being the nucleus of the society that is expected to mark his presence in history effectively and efficiently but by preserving and enriching his cultural and civilizational peculiarities. Such an achievement may add new dimensions to human life as a way to qualify human being for the successful completion of his historical mission as it is expected to be performed in this life as a preparation for the life of the hereafter. It is the Islamic Weltanschauung, as a vital pre-requisite in such a context.

Undoubtedly, the above mentioned approach may help us to realize the need to focus, in building our educational system and in designing our educational curricula and teaching approaches, on the cultural dimension of the process of education; that is, a project that seeks to promote a new culture of life as a psycho-social climate

17 A. Benbouzid, Refonte de la Pédagogie en Algérie. Défis et Enjeux d'une Société en Mutation (Recasting of Pedagogy in Algeria, Challenges and Issues of a Changing Society), Bureau de l'UNESCO pour le Maghreb, 2005. 
that enable people to compete with major global models through its cultural authenticity.

From this civilizational perspective, the educational problem becomes a challenge of how to re-qualify the contemporary Muslim man in such a way to enable him to move from the state of being a backward man, unable to create and achieve his own ambitions in history to that of a civilized one who understands and move forwards to fulfil the requirements of his historical mission as prescribed by the society's cultural frame of reference, that is, Islam.

A deep reflection in this perspective, may enables us to conclude that education as the process of civilizing the Muslim man is the basis upon which any educational project, in the Muslim and Arab lands, is set upon. Any educational project that cannot prepare human being in order to be able to successfully fulfil his historical mission is a project that has lost the justifications of its existence and the conditions of its continuation in history.

Such a perspective to deal with the educational problem becomes more required than ever if we are to control the essential factors of the educational problem as we are facing it in our Muslim world, in order to turn them into factors of solution as a starting point of resolving the entire civilizational problem.

In our view, this vision becomes more necessary when we look at what characterizes the daily life of the Arab Muslim person in general, and the Algerian person in particular, from the manifestations of backward thinking, undisciplined behaviour, poor performance, and the manifestations of disability, mediocrity, laziness, persistent fatigue, collective dependency, insulting and wastefulness in all walks of life, emotional dealing with events, people and ideas, the primacy of the logic of trust over the logic of righteousness, opportunism in behaviour, individual and collective ego inflation, living the past in the present, etc.

As a matter of fact, the civilizational project cannot be achieved unless a purposeful and systematic process of education that aims to the eradication of those backward features is undertaken in an efficient manner. Otherwise, such a project will be in vain.

Perhaps the roots of our inability and decline to make the required shift from backwardness to civilization is due to the fact that human being, as the central factor in this process, has suffered 
from a prolonged damage that has lasted many centuries, making him as a kind of chronic disease that requires exceptional efforts to be cured and eliminated.

Even though the different movements of renaissance in the Arab and Muslim lands had made considerable efforts, they have not yet paid attention to the human factor in the appropriate and required manner.

\section{Conclusion}

In this article, we dealt with the issue of the methodological considerations that must be taken into account in formulating the educational problem in Arab and Muslim countries, specifically in Algeria. Through the analysis and the discussion, it became clear to us that these considerations are an indispensable necessity for the researcher who wants to understand the educational problem correctly and as it really is. On this basis, we affirm that the systematic aspect of dealing with research problems is a fundamental issue that we recommend new researchers in particular, to pay attention to if they want to grasp systematically the problems, they deal with in any study concerned with educational problem in the Arab-Muslim lands.

\section{References}

Abbassi, M. Mushkilāt Tarbawiyah fì al-'Ālam al-Islāmī, (Problems of Education in the Muslim World). $2^{\text {nd }}$ edition, Mecca al-Mukarramah, Saudi Arabia: al-Manara Publishing House, 1989.

Abbassi, Madani. Al-Nawiyah al-Tarbawiyyah fì al-Bilād alIslamiyyah (Quality Education in the Muslim World: Epistemological Analysis of the Educational knowledge). $1^{\text {st }}$ edition, Maktab at-Tarbiyah al-Arabi li Doualil Khalij, Saudi Arabia, 1989,

Benbouzid, A. Refonte de la Pédagogie en Algérie. Défis et Enjeux d'une Société en Mutation. Recasting of Pedagogy in Algeria, Challenges and Issues of a Changing Society, Bureau de l'UNESCO pour le Maghreb, 2005.

Bennabi, M. Wijhah al- 'Álam al-Islāmī (Islam in History and Society). $5^{\text {th }}$ edition, Damascus, Syria: Dār al-Fikr Damascus, Syria: Dār al-Fikr, 1986. 
Moore, T, W. Philosophy of Education: An Introduction. $2^{\text {nd }}$ Edition, London and New York: International Library of Philosophy of Education, Routledge and Kegan Paul, 1986.

Nakib, Omar. "Malik Bennabi's Ideas and Views on Civilization and the Development of Society. Perspectives on Education". Ph.D Thesis, Universiti Putra Malaysia, 2004, (non-published).

Syed Muhammad Naquib Al-Attas's. "The Concept of Education in Islam", and Malik Bennabi's "Wijhatul Alam al-Islami" (Islam in History and Society).

Syed Naquib al-Attas. "The Concept of Islamic Education". The keynote address delivered at the "First World Conference on Muslim Education”, Mecca al-Mukarramah, 1977. 
Nakib, Remark on the Conceptualization of the Educational Problem 